\title{
Evidence on the Effect of Government Debt on Country Economic Growth
}

\author{
Manuel G. Russon \\ St. John's University \\ Farok A. Vakil \\ St. John's University \\ Vipul Bansal \\ St. John's University
}

The debate continues as to whether the effect of government debt and its effect on real economic growth is positive or negative. Some posit that country Real Economic Growth increases with higher public debt while others argue that Real Economic Growth decreases with higher public debt. Real economic growth is modeled as a non-linear function of government debt as a percentage of GDP. Cross section data for Percent Change in Real GDP and Debt as a Percent of GDP for 208 countries was used for years 2011 to 2019. A parameterized nonlinear regression model finds Real Economic Growth to increase to a point corresponding to reasonable levels of debt and then decrease for excessive levels of debt. This study finds that growth is invariant to the size of the economy.

Keywords: real GDP, debt, economic growth

\section{INTRODUCTION}

Policy makers and academics spend much time and resources theorizing and analyzing the possible effects of government debt on real economic growth. A synthesis might be advanced that government deficits and debt might stimulate short term economic growth, but that excessive debt might diminish the rate of economic growth over the longer term. This arises as a large government sector becomes permanent, and that government spending on goods, services and infrastructure might not be done with the same primary aim toward efficiency and cost minimization that market forces might otherwise dictate in a competitive market.

This research investigates the relationship between government debt and real economic growth across global economies. While the microeconomics and econometrics of such an investigation would be unwieldly at best, and a nightmare at worst, especially if done from a short term, time series perspective. This research undertakes to analyze this phenomenon using a macro, top-down analysis of the phenomenon based on averages from a cross-section perspective.

This research discovers and parameterizes a non-linear model of country real gdp growth as a function of debt. We focus on the long-term effect of debt on growth and not with short term macroeconomic effects that increased spending might have. We conclude that increasing the debt to gdp ratio from $0 \%$ to 
approximately $50 \%$ generally enhances real economic growth, but the debt levels exceeding that level leads to lower real economic growth. Policy makers, academics and private sector actors will be interested in the conclusions of this research.

\section{LITERATURE REVIEW}

DiPeitro and Anoruo (2012) studied the effect of public debt and real economic growth for a panel of 175 countries. They concluded that both the size of government and the extent of government indebtedness have negative effects on economic growth. Similarly, Calderón and Fuentes (2013) examined large panel data of countries for $1970-2010$. Their results support the notion of a negative effect of public debt on growth, but add that strong institutions, high quality domestic policies, and outward-oriented policies partly mitigate this adverse effect.

In line with the previous two studies mentioned, António and Alves (2015) study the effect of public debt on economic growth for annual and 5-year average growth rates for 14 European countries from 1970 until 2012. They, too, find a negative non-linear relationship between the level of debt and growth. Their results show a maximum negative impact of around $-0.04 \%$ and $-0.03 \%$ for each $1 \%$ increment of public debt, for annual and 5-year average growth rates, respectively.

Megersa (2015) examines the relationship between economic growth and total public debt. The study found the relationship between total public debt of low-income Sub-Saharan African economies and their economic growth was well shaped.

Several years after the financial crisis of 2007-2008 in the USA, some studies examined the relationship between government debt and economic growth. De Rugy and Salmon (2020) concluded that a large amount of government debt has a negative impact on economic growth potential. They found that the impact becomes more pronounced with increase in government debt. Based on their study, and its current fiscal path, the effects of a large and growing public debt ratio in of the United States economic growth over the coming 30-year period could amount to a loss of $\$ 4$ trillion or $\$ 5$ trillion in real GDP. It translates into $\$ 13,000$ per capita, by 2049 .

In sum, debt and deficit spending may aid local economies in time of recession via the need to stimulate the economy. Long term, however, elevated debt levels seem to lower economic growth. But Megersa found a bell-shaped effect for Sub-Saharan African Economies.

This research reconciles and synthesizes the results of the research and may identify the optimum level of debt.

\section{DATA}

Cross section data for Percent Change in Real GDP and Debt as a Percent of GDP for 208 countries was taken from Wikipedia for years 2011 to 2019. Averages for both were computed and used as dependent and independent variables, respectively. Three observations were eliminated due to outlier status (Venezuela, Libya, Yemen). The database was further limited to countries with population size greater than 2.5 million. The resulting database was 126 observations.

Figures 1-2 display histograms of Percent Change in Real GDP and Debt as a Percent of GDP. Both are slightly skewed to the right. 
FIGURE 1

HIST. OF RGDP GROWTH

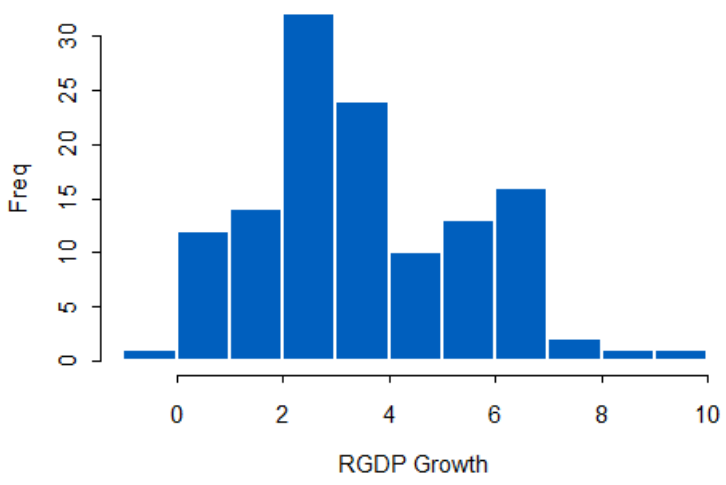

FIGURE 2

HIST. DEBT PCT GDP

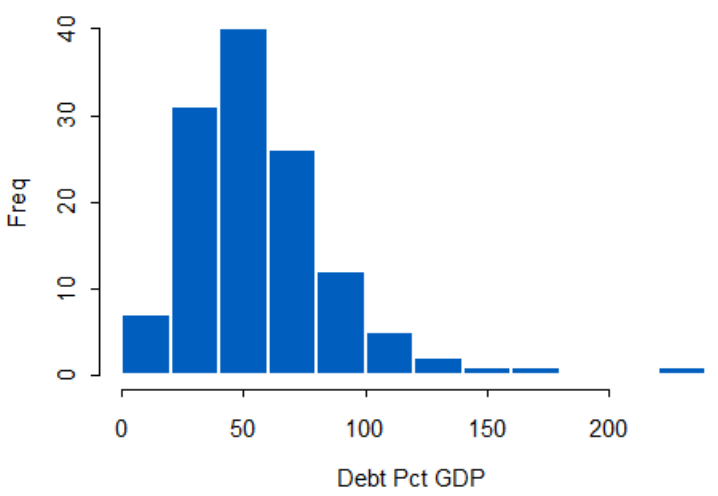

Table 1 displays descriptive statistics of both variables.

TABLE 1

DESCRIPTIVE STATISTICS

\begin{tabular}{|l|l|l|l|l|l|l|l|l|l|l|}
\hline & Min. & Q1 & Mean & Med. & Q3 & Max. & $\begin{array}{l}\text { Std. } \\
\text { Dev. }\end{array}$ & Skew. & Kurtosis & n \\
\hline $\begin{array}{l}\text { RGDP } \\
\text { Growth }\end{array}$ & 0.29 & 2.07 & 3.52 & 3.25 & 5.12 & 9.25 & 2.03 & 0.45 & -0.38 & 126 \\
\hline $\begin{array}{l}\text { Debt Per } \\
\text { GDP }\end{array}$ & 0.10 & 37.30 & 57.52 & 51.55 & 70.03 & 223.8 & 32.60 & 1.83 & 50.92 & 126 \\
\hline
\end{tabular}

Figure 3 displays a scatterplot of RGDP Growth vs. Debt as Pct GDP with a local regression spline overlay and country name as the plot character. The scatterplot clearly demonstrates that as Debt as a Percent of GDP increases, RGDP Growth increases to a point and then decreases. This is consistent with the results of Megersa (2015) noted above even though Megersa asserted results for Sub-Saharan Africa only. 
FIGURE 4

RGDP GTH V DEBT/GDP

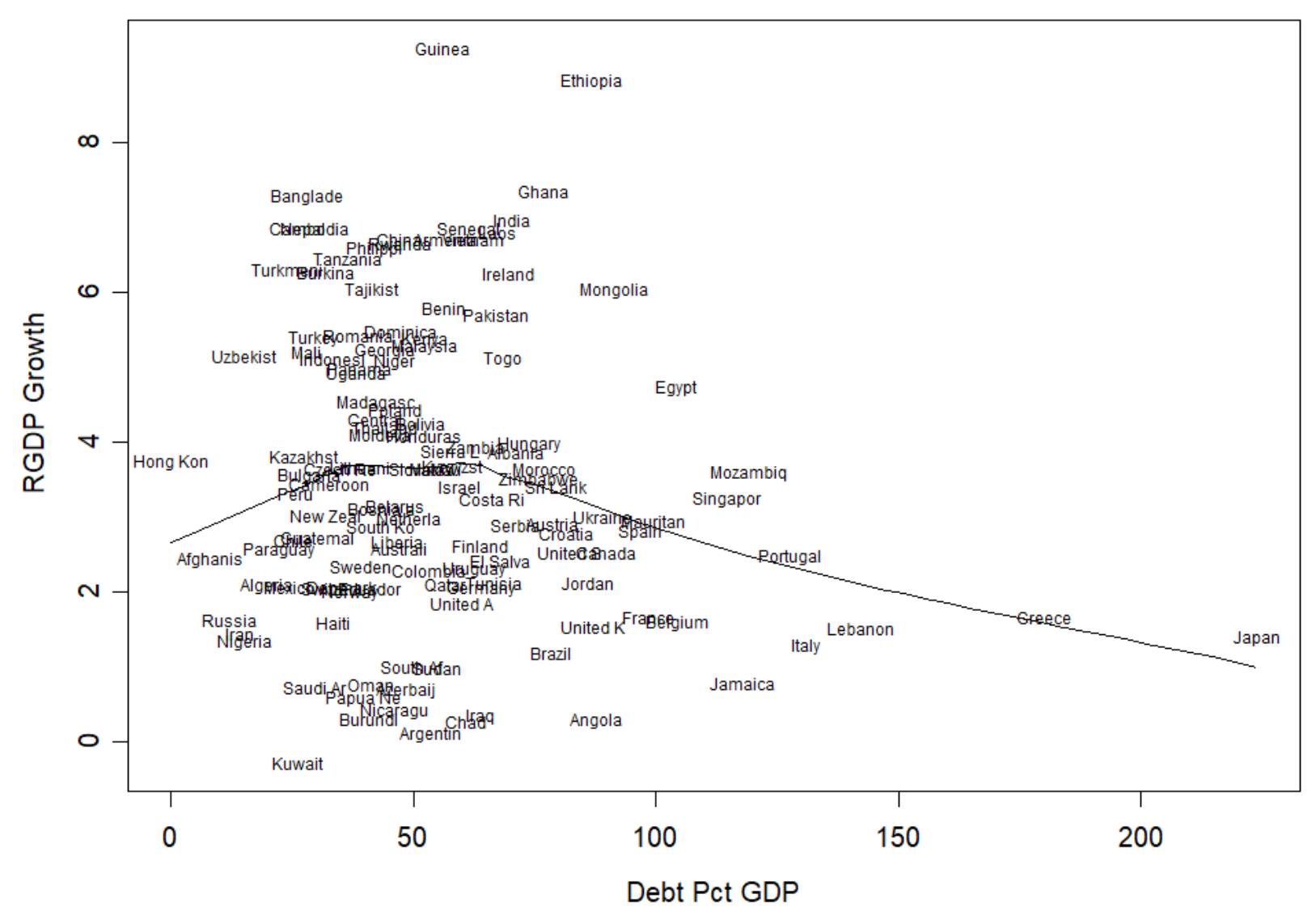

The underpinnings, dynamic processes and linkages leading from changes in Debt as Pct of GDP to RGDP Growth are numerous and complex. Even though the model presented here is posited in terms of averages and does not address the econometric intricacies of causality and timing, clearly some growthdebt dynamic is evident.

\section{MODEL AND METHODOLOGY}

The question that should be answered is if this is indeed a statistically significant result. The functional specification is given in Eqn. 1, below:

$\%$ Change in rgdp $=\mathrm{f}($ debt $\%$ gdp $)$

where: \% Change in rgdp - 9-year average year over year percent change in Real GDP

Debt \% gdp - 9-year average ratio of government debt to GDP

The twin negative and positive signs above debt \% gdp in Equation 1 indicate the hypothesis that, per Messgara (2015) and Figure 3, as debt \% gdp increases, \% change in rgdp will increase to a point and then decrease beyond.

The non-linear, parameterized model of the debt/growth relationship to be estimated is given in Equation 2, below: 
$\%$ Change in $\operatorname{rgdp}=b^{*} \exp ^{\left(-(\operatorname{debt} \% g d p-m a x)^{\wedge} 2 / d i s p\right)}+\mathrm{e}$

Equation 2 is a negative exponential equation mimicking a normal, bell-shaped curve. It peaks at max and descends on either side a rate dictated by disp. The equation is linear in the scale coefficient, $b$.

where: $\max$ - the peak in the function

disp - a measure of dispersion akin to standard deviation

$b \quad$ - scale coefficient for the exponential function

The model will be estimated using R, the statistical program. As Equation 2 is inherently nonlinear in the parameters max and disp, the nonlinear iterative estimation $\mathrm{R}$ algorithm $n l s$, will be used to estimate parameters. The deployed $\mathrm{R}$ function call is given in Equation 3, below.

fit Model <- nls $\left(\%\right.$ change in $\operatorname{rgdp} \sim \mathrm{b}^{*} \exp \left(-(\operatorname{debt} \% \operatorname{gdp}-\max )^{\wedge} 2 / \mathrm{disp}\right)$

start $=$ list $(b=0, \max =50$, disp $=50)$

\section{RESULTS}

The nonlinear iterative regression results from $\mathrm{R}$ are presented in Table 2, below.

$\%$ Change in $\operatorname{rgdp}=3.81^{*} \exp ^{\left(-(\mathrm{debt} \% \mathrm{gdp}-55.62)^{\wedge} 2 / 68.80\right)}+\mathrm{e}$

TABLE 2

NON-LINEAR ITERATIVE REGRESSION RESULTS

\begin{tabular}{|c|c|c|c|}
\hline & Value & Std. Error & t-value \\
\hline $\boldsymbol{b}$ & 3.81 & 0.23 & 16.49 \\
\hline Max. & 55.62 & 10.97 & 5.06 \\
\hline Disp. & 68.80 & 19.80 & 3.47 \\
\hline & & & \\
\hline $\mathrm{F}=21.7$ & (F-prob. $=.008)$ & $\mathrm{R}^{2}=.050 ; \mathrm{df}=122$ & $\mathrm{SE}=1.99$ \\
\hline
\end{tabular}

Importantly, the F-statistic is significant at $1 \%$. As well, all three parameters are statistically significant at $1 \%$ LOS. The nonlinear estimation results indicate that the maximum $\%$ change in rgdp occurs at debt $\%$ gdp level of approximately $55.6 \%$ and diminishes on either side. The estimate of dispersion is $68 \%$.

The explanatory power of the model as measured by R-squared for the non-linear model is low at 5\%. Hence, only 5\% of the variation in Real GDP Growth can be explained by Debt Pct of GDP. Further research should investigate other important variables.

The parameterized bell-shaped relationship and estimated above is confirmed in Figure 4, below. 
FIGURE 14

ACT AND MODELED RGDP GTH V DEBT

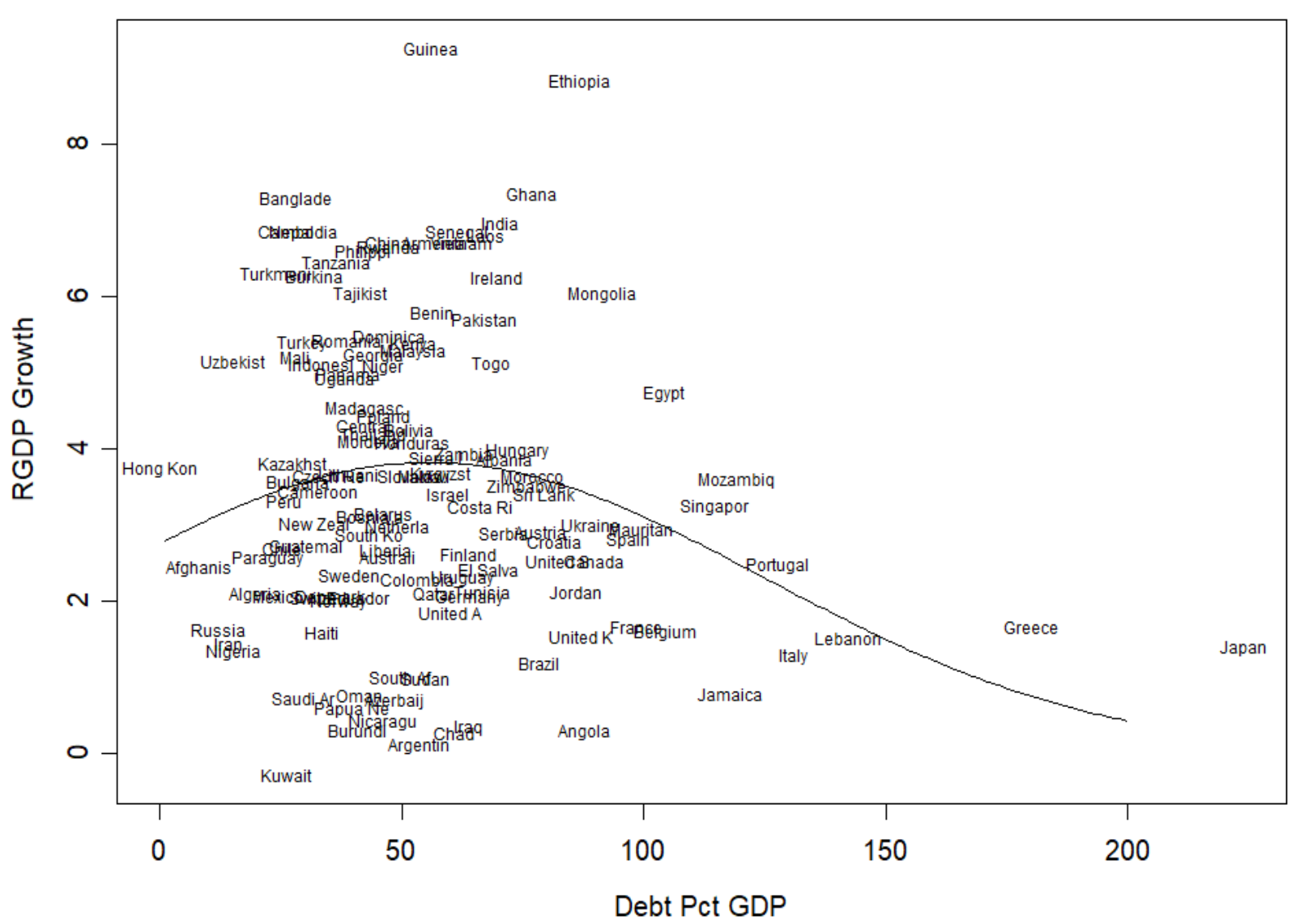

We concede that a slightly different distribution might result in a slightly better fit. For example, a beta, gamma or Weibull function slightly skewed to the right might model the growth/debt phenomenon with slightly higher explanatory power. But the fundamental result and conclusion presented here is unaltered as Debt Pct of GDP increases, Real GDP Growth increases to a point, and then decreases.

One variable which does not appear to be instrumental is the population size of the country. Consider data portrayed in Figure 4. China, with a large population and Russia, with a small population, both have relatively low debt loads. China, however, has a high growth rate and Russia has a low growth rate. Similarly, consider the US, with a large population, and Greece with a small population. Both have relatively high debt loads and both have low Real GDP Growth rates. So, based on casual empiricism, population size does not affect Real GDP Growth.

\section{CONCLUSIONS}

This research reinforces the suggestions and assertions of economists and policymakers that high public debt loads ultimately tend to decrease real economic growth rates. The research, however, advances the literature by concluding that growth rate might increase with debt load over low values of debt. Also, growth is held to be invariant to size of the economy.

Further research should address the question of why some countries with low debt to GDP ratios experience high growth rates while others experience low debt loads. Variables such as population growth or political freedom might be important. 
However, apart from possibilities arising in further research, the results presented here point to an important public policy prescription. That policy prescription is that countries should be very wary of high debt loads which will lead to low levels of real economic growth.

\section{REFERENCES}

Alfonso, A., \& Alves, J. (2015). The Role of Government Debt in Economic Growth. Review of Public Economics, 215(4), 9-26.

Calderón, C., \& Fuentes, J.R. (2013). Government Debt and Economic Growth. IDB Publications (Working Paper) 4641, Inter-American Development Bank.

de Rugy, V., \& Salmon, J. (2020). Debt and Growth: A Decade of Studies. Mercatus Center, George Mason University, Policy Brief.

DiPeitro, W.R., \& Anoruo, E. (2012). Government size, public debt and real economic growth: A panel analysis. Journal of Economic Studies, 39(4), 410-419.

Keynes, J.M. (1936). The General Theory of Employment, Interest and Money. Macmillan, p.472.

Megersa, K.A. (2015). The Laffer curve and the debt-growth link in low-income Sub-Saharan African economies. Journal of Economic Studies, 42(5), 878-892. 